\title{
Sensitive technique for detecting subclinical lead neuropathy
}

\author{
ANNA MARIA SEPPÄLÄINEN and SVEN HERNBERG \\ Institute of Occupational Health, Helsinki, Finland
}

Seppäläinen, A. M., and Hernberg, S. (1972). Brit. J. industr. Med., 29, 443-449. Sensitive technique for detecting subclinical lead neuropathy. Subclinical neuropathy was studied in 39 male lead workers. Although 31 had a diagnosis of poisoning, all were without clinical signs of neurological impairment. A standard electromyogram revealed abnormalities (fibrillations and/or diminished number of motor units) in 24 men. The mean maximum conduction velocities (MCV) of the ulnar and median nerve were significantly lower in the group of lead workers as compared with an age-matched control group. Measurement of the conduction velocity of the slower fibres (CVSF) of the ulnar nerve proved to be a very sensitive indicator of lead damage. This measurement was done as a modification of Hopf's technique using a partial antidromic block. A combination of this variable and the distal latency of the median nerve discriminated lead workers from controls better than any other combinations. The findings are consistent with slight neuropathy. They further show that lead also affects certain portions of the fibres in the proximal part of the nerve.

The neurophysiological findings of the lead workers were collated to form a neurophysiological score (NF score). This score was used to compare the neurophysiological state with the degree of present lead effect, as judged from a rigid classification based on defined subjective symptoms and results of laboratory tests. There was poor agreement between the severity of lead effect and the NF score. No isolated laboratory test correlated with the neurophysiological findings.

From these results it appears that subclinical nerve damage can be detected in lead workers with no clinical neurological symptoms. Measurement of the CVSF is a particularly sensitive method for this purpose. The lack of correlation between the severity of subclinical nerve damage and the intensity of lead effect, as judged by commonly used criteria, suggests that nerve damage is produced independently of other manifestations of poisoning. This observation indicates the need for further studies on the value of present acceptable limits of lead exposure from the point of view of the nervous system.

Improvements in occupational hygiene together with regular medical supervision of exposed workers have caused a drastic reduction in severe neurological manifestations of industrial lead poisoning during the last decades, but this does not rule out the possibility of subclinical nerve damage. However, few studies dealing with this problem have been published. 
men with heavy occupational exposure. None had clinical neurological abnormalities. The mean MCV of the lateral popliteal nerve of the exposed men did not differ from that of an unexposed control group, but several exposed subjects had a diminished ratio of the muscle action potential amplitudes following stimulation at the knee and at the ankle. The conclusion was that although the MCV was normal, conduction was slowed in some fibres and this caused a dispersal of the muscle action potential.

Since the MCV remains normal as long as a portion of the fastest fibres is intact, more sensitive methods are obviously needed to detect early or partial damage in peripheral nerves. We have tried to develop such methods and to evaluate their usefulness in lead poisoning. The present paper reports on these studies.

\section{Material and methods}

\section{Subjects}

The exposed group comprised 39 male lead workers. Their mean age was 36.1 years with a standard deviation of 11.7 (range 18 to 63 years). They had been exposed for periods ranging from 2.5 months to 22 years. A diagnosis of lead poisoning (class I to III, see later) was made in 31 cases. The remaining eight men had excessive or increased absorption but were without symptoms of poisoning at the time of examination. On some previous occasion, 15 of the men suffering from lead poisoning in this study and five of the symptom-free men had suffered from clinical lead poisoning. Seventeen of the subjects came from two lead scrap smelteries, seven from a polyvinylchloride plastic plant, and five from two storage battery factories. Another five were engaged in ship-breaking and three in welding and repair of sulphuric acid containers. The remaining two had been mixing red lead $\left(\mathrm{Pb}_{3} \mathrm{O}_{4}\right)$ into crystal glass mass.

According to measurements made during the last three years, the concentration of lead in the air of the lead smelteries was some 10 to 20 times the threshold limit value of $0.2 \mathrm{mg} / \mathrm{m}^{3}$. Similarly, poor conditions prevailed in one of the accumulator factories. The other showed concentrations around $0.2 \mathrm{mg} / \mathrm{m}^{3}$. No measurements had been performed in the other work-places. Use of personal protective equipment was common.

Other diseases or conditions that could cause neuropathy were excluded in all cases. Special attention was given to the exclusion of alcoholism, diabetes, renal failure, neurological diseases, and exposure to toxic solvents. All electrophysiological measurements were performed either before the start or during the two first days of chelation therapy, if given.

\section{Classification of degree of lead absorption}

To provide a basis for comparisons between the neurophysiological findings and the severity of lead absorption and/or poisoning, we tried to group the subjects into five well-defined categories. One of us (S.H.) made the classification without any knowledge of the neurophysiological findings. The criteria were as follows:
Class I Severe clinical poisoning Any of the following symptoms or signs in combination with symptoms belonging to class II and III and/or laboratory results of class IV:

colic (severe abdominal cramps of intermittent nature) diffuse abdominal pain (daily for at least 2 weeks) paresis or paralysis (not found in a single case) encephalopathy (not found in a single case).

Class II Moderate clinical poisoning Clinical poisoning without the symptoms of class I. At least three of the following symptoms together with the symptoms of class III and the laboratory results of class IV:

diffuse abdominal pain (daily for less than two weeks or occasionally for any longer period)

nausea (regular indigestion and/or occasional vomiting) constipation (no defaecation for three days or more, or very hard stools for one week or more)

weight loss $(=3 \mathrm{~kg})$

headache (for at least three days per week)

distinct general fatigue or somnolence

muscular exhaustibility

tremor

myalgia, paraesthesiae, arthralgia

anaemia (haemoglobin below $11 \mathrm{~g} / 100 \mathrm{ml}$, other causes excluded).

Class III Mild clinical poisoning Absence of symptoms and signs of class I. Less than three of the symptoms and signs of class II and/or any of the following symptoms and signs in combination with the laboratory results of class IV:

occasional abdominal discomfort

mild fatigue or muscular exhaustibility

uncertain myalgia or paraesthesiae

slight anaemia (haemoglobin 11-13 g/100 ml).

Class IV Excessive absorption No subjective symptoms. Haemoglobin $<13 \mathrm{~g} / 100 \mathrm{ml}$. One or both of the following laboratory tests positive:

blood lead more than $80 \mu \mathrm{g} / 100 \mathrm{ml}$

urinary ALA more than $25 \mathrm{mg} / \mathrm{l}$.

Class V Increased absorption No subjective symptoms. One or both of the following findings:

blood lead $40-80 \mu \mathrm{g} / 100 \mathrm{ml}$

urinary ALA $10-25 \mathrm{mg} / 1$.

The distribution of subjects into different classes is shown in Table 2. None had objective clinical neurological abnormalities.

\section{Controls}

The controls were pair-matched for age with the exposed subjects. Of the 39 men used as controls, 16 were college or university graduates (physicians, psychologists, engineers) and 23 were skilled or unskilled workers (farmers, drivers, mechanics, manual labourers). None of the controls had had any known exposure to lead or other toxic industrial agents. There were no indications of neurological disease.

\section{Laboratory methods}

The concentration of lead in whole blood was determined from duplicate samples after wet oxidation using a 
dithizone method (Keenan, Byers, Saltzman, and Hyslop, 1963), urinary $\delta$-aminolaevulic acid (ALA) according to Grabecki, Haduch, and Urbanowicz. (1967), and haemoglobin using routine methods.

\section{Electrophysiological methods}

A standard electromyographic (EMG) examination was performed on all exposed subjects, using a Disa electromyograph and concentric needle electrodes. At least one wrist extensor and one intrinsic hand muscle were always examined; in all, from four to eight muscles were studied. No needle electrode EMG was performed on the controls. The patterns of maximal contraction, shape, duration, and amplitude of single motor units, as well as possible spontaneous activity during muscular relaxation, were noted.

Maximal motor conduction velocity The MCV of the median, ulnar, and lateral popliteal nerves was measured for all exposed subjects and controls with the standard method (Hodes, Larrabee, and German, 1948). The room temperature was $25^{\circ} \mathrm{C}$ to $26^{\circ} \mathrm{C}$ and the skin temperature at the proximal stimulation point $31.5^{\circ} \mathrm{C}$ to $34^{\circ} \mathrm{C}$ in the arms and $31.5^{\circ} \mathrm{C}$ to $33.5^{\circ} \mathrm{C}$ in the legs. The nerves were stimulated with a skin electrode at two points (arms at elbow level and at $2 \mathrm{~cm}$ above the wrist fold; legs-just above the head of the fibula and at the ankle) along the course of the nerve with supramaximal square wave stimuli of 0.3 to $1.0 \mathrm{~ms}$ duration from a Disa Multistim. The muscular response was recorded with skin electrodes taped on the belly and tendon of the opponens pollicis, the abductor digiti minimi, and the extensor digitorum brevis muscles. The responses were amplified with the electromyograph. The latencies were determined using a Telequipment oscilloscope with the aid of the Multistim potentiometer. The distance in millimetres between the stimulation points was carefully measured with a tapemeasure.

Conduction velocity of slower fibres (CVSF) This was measured using a partial antidromic block. This technique, developed by one of us (Seppäläinen 1971), is a modification of the method first described by Hopf (1962). The principle is as follows: If the nerve is simultaneously stimulated at two different points, the antidromic volley from the distal stimulus point stops the orthodromic volley from the proximal point on its way to the muscle. Thus only one muscular response is obtained, i.e., that corresponding to the distal stimulus. If, on the other hand, the proximal stimulus is sufficiently delayed, two successive muscular responses, corresponding to each of the stimuli, can be recorded. The interval between the stimuli is then gradually shortened until the second response begins to decrease. Some fibres are now being inhibited by the antidromic volley although most of them are still conducting the impulse. The latency of the slow fibres between the stimulation points is obtained by subtracting $1 \mathrm{~ms}$ (the refractory period of the nervous fibres) from the shortest interval between paired stimuli with full response. The CVSF can then be calculated by dividing the distance by the latency time.

According to a pilot study, the CVSF is the same in the right and the left arms. Because of this, we studied only the right ulnar nerve. The experimental arrangement is shown in Figure 1. The first stimulus point was at wrist level and the second on the distal part of the upper

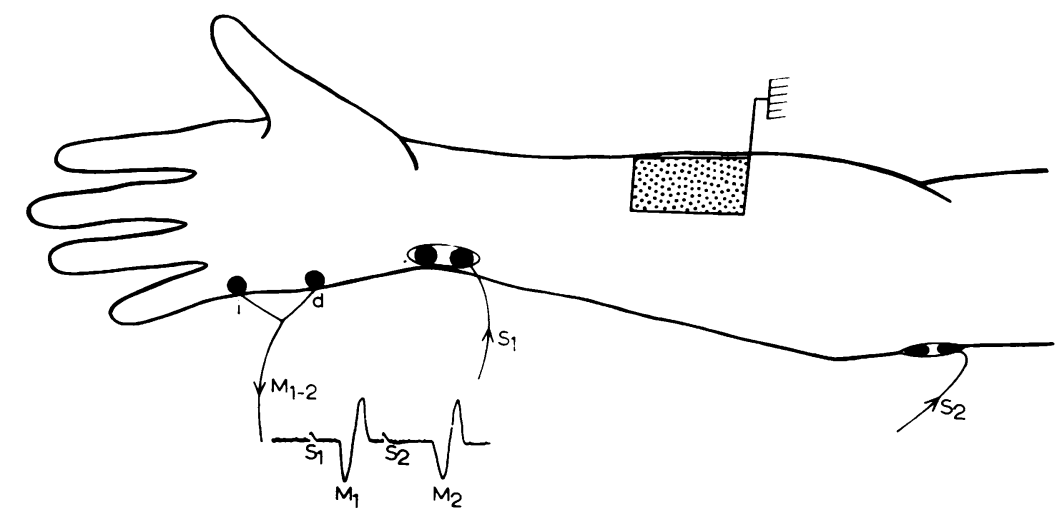

FIG. 1. The experimental arrangement for measurement of the CVSF of the right ulnar nerve.

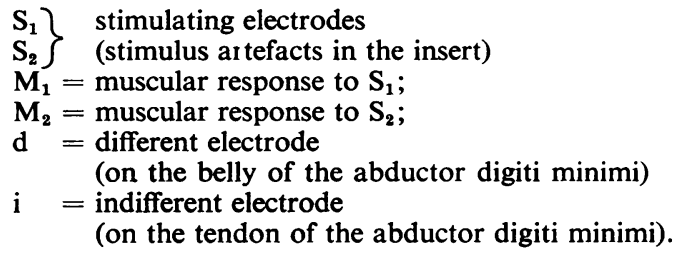


arm, a few centimetres proximal to the sulcus nervi ulnaris. We led off the muscular response to the electromyograph and the oscilloscope with skin electrodes on the belly and tendon of the abductor digiti minimi. Photographic techniques were unnecessary because the shortest interval between paired stimuli with full response to both of them could be directly read from the Multistim potentiometer. The accuracy of the measurements was $0.1 \mathrm{~ms}$. The CVSF was then calculated as described above. Technically, the measurement is fairly easy to perform. As the nerve is always close to the skin, a supramaximal stimulus can be achieved without discomfort and a long enough distance for clear demonstration of both muscular responses is easily reached. We feel that using the CVSF of the ulnar nerve offers an advantage as compared to the amplitude ratio studies of the lateral popliteal nerve; supramaximal stimulation of the latter, especially at the ankle, is not always easy, which results in decreased reliability.

All neurophysiological findings The findings in exposed subjects were collated to form a neurophysiological score (NF score), the components of which are shown in Table 1. The borderlines between normal and abnormal are based on studies of 120 healthy subjects between 20 and 60 years of age under the same experimental conditions (Seppäläinen and Toivakka, in preparation). The borderlines are so chosen that a healthy normal always has a score of 0 .

\section{Results}

A summary of the neurophysiological findings is given in Table 2, which also shows the structure of the NF score of each subject. These scores could be calculated for 32 subjects only. The first seven were studied before we were able to measure the CVSF because of incomplete equipment. A comparison between the NF score and the degree of present lead effect is shown in Figure 2. Superficially, there may seem to be some associations for those without previous episodes between high scores and the severity of present poisoning, but the Spearman rank order correlation coefficient did not reach commonly

\section{TABLE 1}

\section{SCORING OF NeURophysiological Findings} (NF SCORE)

1. MCV of the median nerve $<50 \mathrm{~m} / \mathrm{s}$

2. Distal latency of the median nerve $\geqq 4.8 \mathrm{~ms}$

3. MCV of the ulnar nerve $<50 \mathrm{~m} / \mathrm{s}$

4. CVSF of the ulnar nerve $30-40 \mathrm{~m} / \mathrm{s}$

$$
\text { ,, , , , }<30 \mathrm{~m} / \mathrm{s}
$$

5. MCV of the lateral popliteal nerve $<45 \mathrm{~m} / \mathrm{s}$

6. Fibrillations in 1-2 muscles (EMG) in 3 or more muscles

7. Diminished number of motor units in maximal contraction, slight in at least two muscles Moderate diminution of the number of motor units (single units or mixed pattern in at least two muscles) accepted values for statistical significance $(r=0.27$, $P>0.05)$. The results for those with earlier poisoning show no association at all; further, there was no relationship between the NF score and any isolated laboratory test such as lead-in-blood, urinary ALA, or the haemoglobin concentration. These findings suggest that the effect of lead on the peripheral nerves may be either independent of effects on other systems or reflect different temporal events.

A closer analysis of the isolated neurophysiological findings reveals that the EMG was abnormal for 24 subjects. Fifteen had fibrillations (denervation potentials) in one or more muscles, and 16 had a diminished number of motor units. Seven men thus had both findings. These abnormalities are both compatible with peripheral neurogenic lesions. Table 3 shows a comparison between the conduction velocities of the exposed subjects and the controls. The mean MCVs of all three nerves studied were slightly slower in the exposed group. However, marked pathological values of MCV did not occur. The slowest MCV in the forearm was $45 \mathrm{~m} / \mathrm{s}$ and in the lateral popliteal nerve $35.5 \mathrm{~m} / \mathrm{s}$. The mean distal latency of the median nerve was significantly prolonged in the exposed group; we found a latency $>5 \mathrm{~ms}$ several times, the longest one being $6 \cdot 2 \mathrm{~ms}$. This finding indicates a slowing of the conduction in the distal branches of the nerve. The most marked difference between the groups was the reduction of the CVSF of the ulnar nerve among the lead workers. Figure 3 shows that subjects with one or more previous episodes of poisoning had pathological values more often than those poisoned for the first time.

Together with the EMG findings, the CVSF of the ulnar nerve was the most frequently abnormal finding. In order to find out which variables best separated lead workers from controls, a discriminant function analysis was made of the different conduction velocities. The analysis showed that the CVSF of the ulnar nerve and the distal latency of the median nerve formed the best combination $(\mathrm{y}=$ $26.4 X_{1}-222.0 X_{2} ; F=14.93, P<0.001$, when $X_{1}=$ CVSF of the ulnar nerve and $X_{2}=$ the distal latency of the median nerve). Addition of a third variable to the combination did not increase the power of separation significantly.

\section{Discussion}

Experimental studies have shown that lead produces a polyneuropathy characterized by either segmental demyelination or Wallerian degeneration in poisoned guinea-pigs and rats, resulting in reduction of motor nerve conduction velocity (Fullerton, 1966; Schlaepfer, 1969). Considerable variations in interindividual susceptibility seem to exist, however (Schlaepfer, 1969). In contrast to these authors, Hopkins (1970) was unable to produce any lesions 
TABLE 2

Some Data on the Exposed Subjects

\begin{tabular}{|c|c|c|c|c|c|c|c|c|c|c|c|c|c|}
\hline \multirow{2}{*}{\multicolumn{3}{|c|}{ Degree of lead effect }} & \multirow{2}{*}{$\begin{array}{l}\text { Case } \\
\text { no. }\end{array}$} & \multirow{2}{*}{ Age } & \multicolumn{7}{|c|}{ Neurophysiol. findings ${ }^{1}$} & \multirow{2}{*}{ NF score } & \multirow{2}{*}{$\begin{array}{l}\text { Previous } \\
\text { poisoning }\end{array}$} \\
\hline & & & & & 1 & 2 & 3 & 4 & 5 & 6 & 7 & & \\
\hline $\begin{array}{l}\text { Class I } \ldots \\
\text { Severe clinical poisoning }\end{array}$ & $\begin{array}{l}\cdots \\
\cdots\end{array}$ & $\begin{array}{l}\cdots \\
\cdots\end{array}$ & $\begin{array}{c}33 \\
2 \\
6 \\
26 \\
23 \\
----- \\
5 \\
27 \\
17\end{array}$ & \begin{tabular}{|c}
25 \\
58 \\
50 \\
35 \\
43 \\
----- \\
53 \\
25 \\
23
\end{tabular} & $\begin{array}{c}1 \\
--\end{array}$ & $\begin{array}{c}1 \\
1 \\
-- \\
1\end{array}$ & $\begin{array}{c}1 \\
1 \\
\\
-- \\
\end{array}$ & $\begin{array}{c}1 \\
1 \\
x \\
x \\
1 \\
-- \\
2\end{array}$ & $\begin{array}{c}1 \\
1 \\
--\end{array}$ & $\begin{array}{c}1 \\
1 \\
-- \\
1\end{array}$ & \begin{tabular}{c}
1 \\
1 \\
1 \\
\hdashline-- \\
1
\end{tabular} & $\begin{array}{c}4 \\
3 \\
\mathrm{x} \\
\mathrm{x} \\
2 \\
- \\
6 \\
1 \\
0\end{array}$ & $\begin{array}{c}+ \\
+ \\
+ \\
+ \\
+ \\
--- \\
- \\
- \\
-\end{array}$ \\
\hline $\begin{array}{l}\text { Class II } \quad . \quad \ldots \\
\text { Moderate clinical poisoning }\end{array}$ & $\begin{array}{l}\cdots \\
\cdots\end{array}$ & $\begin{array}{l}\cdots \\
\cdots\end{array}$ & $\begin{array}{c}18 \\
16 \\
21 \\
---- \\
1 \\
20 \\
24 \\
22 \\
4 \\
11 \\
15 \\
39\end{array}$ & $\begin{array}{c}30 \\
41 \\
44 \\
---- \\
23 \\
21 \\
28 \\
18 \\
25 \\
37 \\
31 \\
30\end{array}$ & -- & -- & $\begin{array}{c}1 \\
1 \\
-- \\
1\end{array}$ & \begin{tabular}{|c|}
2 \\
$\mathrm{x}$ \\
-- \\
2 \\
1 \\
\\
1 \\
1
\end{tabular} & $\begin{array}{c}1 \\
-- \\
1\end{array}$ & $\begin{array}{c}1 \\
-- \\
1 \\
1 \\
1\end{array}$ & $\begin{array}{c}1 \\
-- \\
1 \\
1 \\
1 \\
1\end{array}$ & $\begin{array}{c}4 \\
x \\
1 \\
---- \\
5 \\
3 \\
3 \\
1 \\
1 \\
1 \\
1 \\
0\end{array}$ & $\begin{array}{c}+ \\
+ \\
+ \\
-- \\
- \\
- \\
- \\
- \\
- \\
- \\
-\end{array}$ \\
\hline $\begin{array}{l}\text { Class III } \\
\text { Mild clinical poisoning }\end{array}$ & $\begin{array}{l}\cdots \\
\cdots\end{array}$ & $\begin{array}{l}\cdots \\
\cdots\end{array}$ & $\begin{array}{c}38 \\
19 \\
37 \\
25 \\
30 \\
34 \\
---- \\
31 \\
7 \\
13 \\
29 \\
32 \\
28\end{array}$ & $\begin{array}{c}63 \\
27 \\
60 \\
48 \\
28 \\
35 \\
---- \\
26 \\
35 \\
22 \\
28 \\
23 \\
35\end{array}$ & \begin{tabular}{|c|}
1 \\
\\
-- \\
1
\end{tabular} \mid & $\begin{array}{c}1 \\
1 \\
1 \\
1 \\
1 \\
1 \\
-- \\
1 \\
1\end{array}$ & $\begin{array}{c}1 \\
1 \\
1 \\
1 \\
1 \\
-1\end{array}$ & \begin{tabular}{|c|}
1 \\
1 \\
1 \\
$x$ \\
$x$ \\
-- \\
1 \\
1 \\
$x$
\end{tabular} & $\begin{array}{c}1 \\
1 \\
1 \\
-- \\
\\
1\end{array}$ & $\begin{array}{c}1 \\
1 \\
\\
-- \\
1 \\
1\end{array}$ & $\begin{array}{r}2 \\
1 \\
1 \\
\\
-- \\
1\end{array}$ & $\begin{array}{l}8 \\
5 \\
4 \\
x \\
x \\
1 \\
- \\
3 \\
2 \\
2 \\
2 \\
x \\
0\end{array}$ & $\begin{array}{l}+ \\
+ \\
+ \\
+ \\
+ \\
+ \\
- \\
- \\
- \\
- \\
- \\
-\end{array}$ \\
\hline 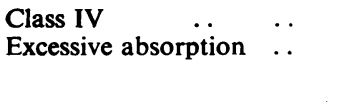 & $\begin{array}{l}\cdots \\
\cdots\end{array}$ & $\begin{array}{l}\cdots \\
\cdots\end{array}$ & $\begin{array}{r}12 \\
8 \\
14\end{array}$ & $\begin{array}{l}46 \\
35 \\
26\end{array}$ & & & & $\begin{array}{l}1 \\
x\end{array}$ & & $\begin{array}{l}1 \\
2 \\
1\end{array}$ & 2 & $\begin{array}{l}4 \\
2 \\
x\end{array}$ & $\begin{array}{l}+ \\
+ \\
+\end{array}$ \\
\hline $\begin{array}{ll}\text { Class V } & \ldots \\
\text { Increased absorption } & \ldots\end{array}$ & $\begin{array}{l}\cdots \\
\cdots\end{array}$ & $\begin{array}{l}\cdots \\
\cdots\end{array}$ & $\begin{array}{c}36 \\
10 \\
--- \\
9 \\
3 \\
35\end{array}$ & $\begin{array}{c}54 \\
43 \\
----- \\
38 \\
39 \\
35\end{array}$ & -- & -- & $\begin{array}{c}1 \\
--\end{array}$ & $\begin{array}{c}1 \\
--\end{array}$ & $\begin{array}{c}1 \\
--\end{array}$ & -- & $\begin{array}{c}2 \\
--\end{array}$ & $\begin{array}{c}5 \\
0 \\
------ \\
1 \\
0 \\
0\end{array}$ & $\begin{array}{l}+ \\
+ \\
- \\
- \\
-\end{array}$ \\
\hline
\end{tabular}

'The numbers of the columns under 'neurophysiol findings' correspond to those in Table 1. The CVSF (column 4) of seven subjects was not measured. Missing data are indicated by $x$.

in the peripheral nerves of 15 baboons poisoned with lead. This was verified by histological examination, EMG, and measurements of the nerve conduction velocity. The nature of lead palsy in man still remains obscure (Hopkins, 1970). Although Simpson, Seaton, and Adams (1964) believe that neuronopathy of the anterior horns is the cause of lead palsy, the findings of Sessa and his colleagues (1965), as well as those of Catton and his co-workers (1970), are all more compatible with peripheral neurogenic lesions, most likely peripheral neuropathy. We are inclined to agree with the latter authors, since our results suggest segmental demyelination with partial damage of the nerve trunks. 

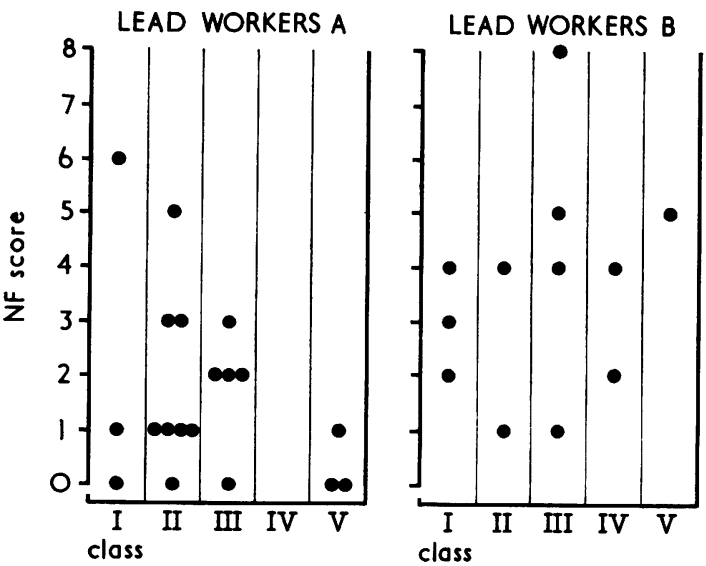

FIG. 2. NF score and present lead effect. For classification of the lead effect, see text.

Lead workers $A=$ first episode of excessive absorption or poisoning

Lead workers $\mathbf{B}=$ subjects with one or more previous episodes of lead poisoning

The animal experiments cited above (Fullerton, 1966; Schlaepfer, 1969) suggest that the segmental demyelination involves only some of the nerve fibres. Because measurement of the MCV is rather insensitive, more refined techniques are needed for demonstrating such damage. The method used by Catton and his team (1970) is an improvement, but still more sensitivity can be obtained by measuring the distal latency of the median nerve and, especially, the CVSF of the ulnar nerve using a partial antidromic block. Both these measurements are technically simple and fairly quick to perform. One problem is that a refractory period of $1 \mathrm{~ms}$ used in the calculations of the CVSF may be slightly too short for the most abnormal cases. Thus the slowest CVSF values measured may seem a little too patho-

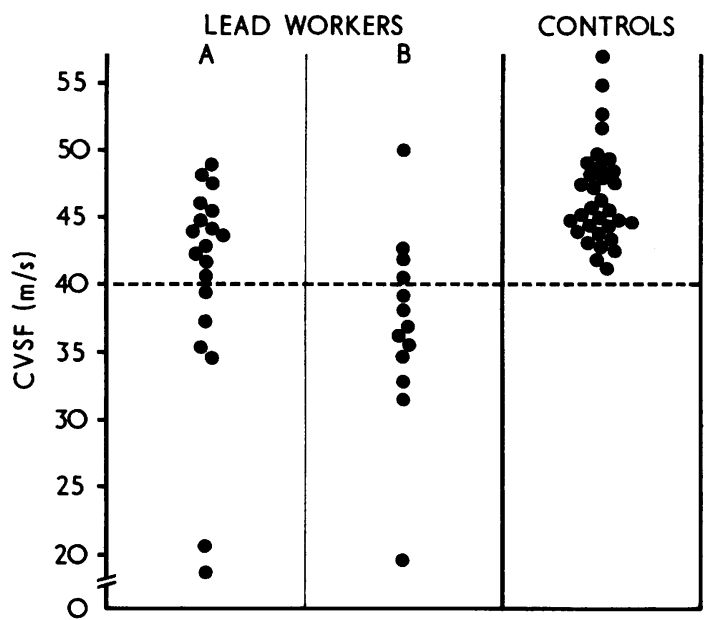

FIG. 3. CVSF of the right ulnar nerve in lead workers $A$, lead workers B, and normal controls.

logical. But in these cases the true CVSF would be far from the normal range anyhow. Measuring the actual refractory period in each subject would, of course, have added to accuracy. However, as the practical significance would have been questionable, we considered it justified to simplify our technique and leave out this cumbersome procedure.

Our results specifically revealed that the slower nerve fibres are being damaged by lead. Moreover, some fibres are damaged not only in the distal part of the nerve, which is known to be vulnerable to noxae of different origins, but also in its proximal part. Another notable finding in concordance with neurogenic lesions was the abundance of EMG abnormalities, i.e., fibrillations and a diminished number of motor units.

TABLE 3

Nerve Conduction Velocity Findings in 39 Lead Workers and 39 Age-matched Controls

\begin{tabular}{|c|c|c|c|c|c|c|c|}
\hline \multirow{2}{*}{\multicolumn{4}{|c|}{ Variable }} & \multicolumn{2}{|c|}{ Mean \pm S.D. } & \multirow{2}{*}{$T$} & \multirow{2}{*}{$P$} \\
\hline & & & & Exposed & Controls & & \\
\hline $\begin{array}{l}\text { Age }(\mathrm{yr}) \ldots \\
\text { MCV }(\mathrm{m} / \mathrm{s}) \text { of the median nerve } \\
\text { Distal latency (ms) of the median nerve } \\
\text { MCV }(\mathrm{m} / \mathrm{s}) \text { of the ulnar nerve } \\
\text { CVSF }(\mathrm{m} / \mathrm{s}) \text { of the ulnar nerve } \\
\text { MCV }(\mathrm{m} / \mathrm{s}) \text { of the lateral popliteal nerve }\end{array}$ & $\begin{array}{l}\cdots \\
\cdots \\
\cdots \\
\cdots \\
\cdots\end{array}$ & $\begin{array}{l}\cdots \\
\cdots \\
\cdots \\
\cdots \\
\cdots\end{array}$ & $\begin{array}{l}\cdots \\
\cdots \\
\cdots \\
\cdots \\
\cdots\end{array}$ & $\begin{array}{r}36 \cdot 1 \pm 11 \cdot 7 \\
55 \cdot 3 \pm 3 \cdot 7 \\
4 \cdot 6 \pm 0 \cdot 6 \\
54 \cdot 0 \pm 5 \cdot 2 \\
39 \cdot 0 \pm 8 \cdot 0 \\
48 \cdot 4 \pm 5 \cdot 1\end{array}$ & $\begin{array}{r}35.5 \pm 11.5 \\
58.6 \pm 3.7 \\
4.0 \pm 0.5 \\
56.7 \pm 3.4 \\
46.6 \pm 3.7 \\
50.7 \pm 3.6\end{array}$ & $\begin{array}{l}4 \cdot 00 \\
5 \cdot 10 \\
2 \cdot 84 \\
4 \cdot 90 \\
2 \cdot 30\end{array}$ & $\begin{array}{l}<0.001 \\
<0.001 \\
<0.01 \\
<0.001 \\
<0.025\end{array}$ \\
\hline
\end{tabular}

${ }^{1}$ Data from 32 exposed subjects and 32 controls 
The authors wish to express their sincere thanks to $\mathrm{Mr}$. Timo Partanen, M.A., and Mrs. Sisko Asp, M.A., for the statistical analyses, and to Mrs. Eeva Marja Lindholm for her valuable technical assistance in performing the neurophysiological tests.

\section{References}

Catton, M. J., Harrison, M. J. G., Fullerton, P. M., and Kazantzis, G. (1970). Subclinical neuropathy in lead workers. Brit. med. J., 2, 80-82.

Fullerton, P. M. (1966). Chronic peripheral neuropathy produced by lead poisoning in guinea-pigs. J. Neuropath . exp. Neurol., 25, 214-236.

Grabecki, J., Haduch, T., and Urbanowicz, H. (1967). Die einfachen Bestimmungsmethoden der $\delta$-Aminolävulinsäure im Harn. Int. Arch. Gewerbepath. Gewerbehyg., 23, 226-240.

Hodes, R., Larrabee, M. G., and German, W. (1948). The human electromyogram in response to nerve stimulation and the conduction velocity of motor axons. Arch. Neurol. Psychiat. (Chic.), 60, 340-365.

Hopf, H. Ch. (1962). Untersuchungen über die Unterschiede in der Leitgeschwindigkeit motorischer Nervenfasern beim Menschen. Dtsch. Z. Nervenheilk., 183, 579-588.

Hopkins, A. (1970). Experimental lead poisoning in the baboon. Brit. J. industr. Med., 27, 130-140.

Keenan, R. G., Byers, D. H., Saltzman, B. E., and Hyslop, F. L. (1963). The 'USPHS' method for determining lead in air and in biological materials. Amer. industr. Hyg. Ass. J., 24, 481-491.

Schlaepfer, W. W. (1969). Experimental lead neuropathy: A disease of the supporting cells in the peripheral nervous system. J. Neuropath. exp. Neurol., 28, 401-418.

Seppäläinen, A. M. (1971). The conduction velocity of slower fibers of the ulnar nerve in adults. Scand. J. clin. Lab. Invest., 27, Suppl. 116, p. 70.

Sessa, T., Ferrari, E., and Colucci D'Amato, C. (1965). Velocita'di conduzione nervosa nei saturnini. Folia med. (Napoli), 48, 658-668.

Simpson, J. A., Seaton, D. A., and Adams, J. F. (1964). Response to treatment with chelating agents of anaemia, chronic encephalopathy, and myelopathy due to lead poisoning. J. Neurol. Neurosurg. Psychiat., 27, 536-541.

Received for publication June 1, 1971 